\title{
Estimation of Humerus Length from Its Segments in Telangana State.
}

\author{
*Dr.Gayatri ${ }^{1}$, Dr.Ashish Kamdi ${ }^{2}$, Dr.Anil.R.Sherke ${ }^{3}$, Dr.Krishnaiah. $\mathrm{M}^{4}$, \\ H.R.Sharada ${ }^{5}$ \\ 1,2,3,4,5. Department of Anatomy Address for communication: Dr. Gayatri, Assistant Professor Department of \\ Anatomy, Kamineni Institute of Medical Sciences, Narketpally- Telangana, Pin code:508 254
}

\begin{abstract}
:
Introduction: The aim of the study was to estimate the length of humerus from the measurements of proximal and distal segments in Telangana State population using regression equation. Helps archaeologists, anthropologists and forensic investigators, to estimate the stature \&identity when a fragment of bone is available. In current studymeasurments of proximal and distal segments of humerus was dervied and the length of the humerus was estimated.

Methods: A total of 30 humeri, 15 right and 15 left were used for this study. Maximum length of humerus, vertical and transverse diameter of proximal segment, transverse diameter and biepicondylar width of distal segment were measured using osteometric board \& Vernier calipers.

Results: With the obtained measurements - descriptive statistics, linear regressions and regression equations for both sides are done. In the right humeri, multiple linear regression of vertical diameter of superior articular surface alone showed significant changes in maximum humeral length contributing up to $85 \%$. In the left humeri, multiple linear regressions of vertical diameter of superior articular surface as well as transverse diameter of inferior articular surface showed significant changes in maximum humeral length $(P<0.001)$.

Conclusion: The result of our study concludes that the length of the humerus can be estimated from the measures of proximal and distal segments of humerus of both sides.
\end{abstract}

Key Words: Proximal and distal segments of humerus, Length, Regression equation, Telangana State population

\section{Introduction}

Estimation of stature has a significant importance in the field of forensic anthropometry. Stature is one of the most important elements in the identification of an individual. "Stature" is one of the most important elements in the identification of an individual. Many different body parts can be used in the estimation of stature. Hence estimation of stature from length of long bones is of practical importance \& has to be population specific $^{[1-4]}$.

In archaeological \& forensic practice, fragments of long bones are often preserved as the only available source to establish identity, and then the stature estimation becomes most important work in such condition. The application of osteometry is of utmost important in forensic medicine. Knowledge of morphometric values of humerus segment is important in order to identify unknown bodies ${ }^{[5]}$.

Also, when the whole of the long bones becomes unavailable in many situations, some methods have been employed for the usefulness of the fragments of long bone such as ulna and tibia (Mysorekaretal., 1984) and humerus (Wright \& Vasquez).So, by knowing the measurements of different segments of the humerus, based on their articular surfaces and muscle attachments, total length of the humerus can be determined (Muñoz et al., 2001).

\section{Material And Methods}

This study was carried on 30 adult dryhumeribone of Telangana State population(right side15; left side 15) of both sexes, at the Kamineni Institute of Medical Sciences, Narketpally.

The maximum length of the humerus was measured by using an osteometric board.

The vertical diameter and the transverse diameter of the superior articular surface of the proximal segment, transverse diameter of the inferior articular surface and the biepicondylar width of the distal segment were measured by using a verniercaliper (fig no 1).

Inclusion criteria: Dried humerus are taken.

Exclusion criteria:Broken, diseased and damaged bones were excluded from the study. The measurements were taken as under: 
1. The vertical diameter of the superior articular surface was measured as the maximum distance between two points on the head of the humerus, in the plane of the tip of greater tuberosity.

2. The transverse diameter of the superior articular surface was measured as the maximum width between two points on the head of the humerus.

3. The transverse diameter of the inferior articular surface was measured as the maximum combined width of the trochlea and the capitulum at the anterior surface.

4. The biepicondylar width was measured as the maximum distance between the medial and the lateral epicondyles.

5. The maximum length of the humerus was measured as the straight distance between the highest point on the head of the humerus and the deepest point on the trochlea.

All the measurements were expressed in centimeters. By using these measurements, minimum, maximum, mean and standard deviation were calculated. For doing the statistical analysis, the SPSS 12.0 version was use

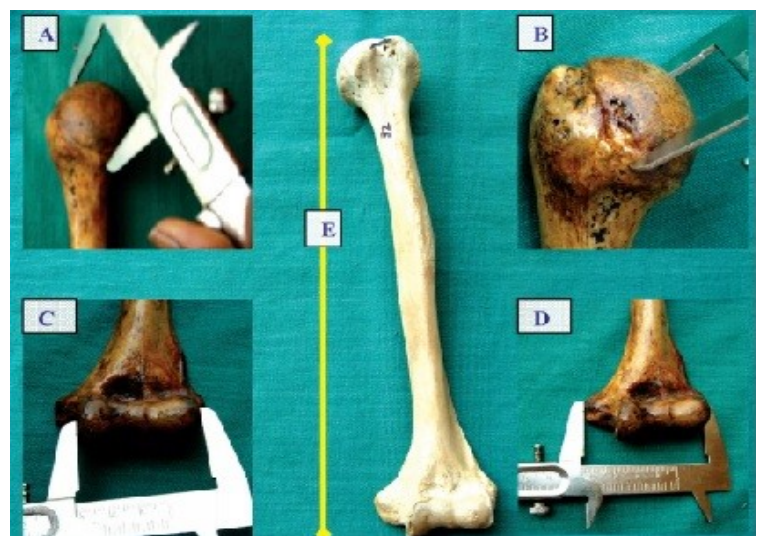

Fig No 1: Showing the measurements of proximal and distal segments of humerus.
A. Vertical diameter of the superior articular surface.
B. Transverse diameter of the superior articular surface.
C. Transverse diameter of the superior articular surface.
D. Biepicondylar width.
E. Maximum length of humerus.

\section{Results}

Statistical analysis was carried on 30 dry adult Telangana Statehumeri. The descriptive statistics, linear regressions and regression equations were done \& results are tabulated.

1. Descriptive analysis: [Table-1, 2, 3] show the mean values of the maximum length of the humerus (MHL) and the proximal and the distal segments of the humeri of both sides. No statistical test was carried out to analyzebecause the right and left humeri did not belong tothe same individuals.

2. Simple linear regression: [Table-4] shows the regression CoEfficient (COE) and the significance (P value) for the dimensions of the proximal and the distal segments of both the humeri separately. On analyzing the proximal segment of the right side, the best results were seen with P1 than P2, while on the distal segment, the best results were seen with D1than D2. On the proximal segment of the left humerus, the best results were obtained with P2 than P1 and on the distal segment with D1 than D2.

3. Simple linear regression equations: Worldwide, the regression formulae have been accepted as of utmost importance in the determination of stature from various anthropometric dimensions $[8,9]$. In the present study, regression formula was related to the dimensions of the proximal and the distal segments of the humerus was derived as under:

\section{Right humerus:}

$\mathrm{MHL}=26.801+1.013 \times \mathrm{PS}$ VD SAS

$\mathrm{MHL}=29.833+0.161 \times \mathrm{PS}$ TD SAS

$\mathrm{MHL}=27.722+0.914 \times \mathrm{DS}$ TD IAS

MHL $=31.047+0.181 \times$ DS BECW

Left humerus:

$\mathrm{MHL}=32.508+0.238 \times \mathrm{PS}$ VD SAS

$\mathrm{MHL}=25.963+2.228 \times \mathrm{PS}$ TD SAS

$\mathrm{MHL}=30.213+0.571 \times \mathrm{DS}$ TD IAS 


\section{$\mathrm{MHL}=32.78+0.254 \times \mathrm{DS}$ BECW}

Multiple linear regression:

Right humerus:In the proximal segment, the vertical diameter of the superior articular surface showed that $\mathrm{R}=0.26, \mathrm{r} 2=.07, \mathrm{P}<0.01$, the other three variables were excluded in this model (non predictors) which meant that out of the 4 variables which were studied, the vertical diameter of the superior articular surface in the proximal segment alone gave a significant maximum humerus length.

Left humerus: The vertical diameter of the superior articular surface in the proximal segment and the transverse diameter of the inferior articular surface showed that $\mathrm{R}=0.13, \mathrm{r} 2=.017$. Both the measures showed significant changes in the maximum humerus length with $\mathrm{P}<0.01$ for the vertical diameter

Table 1

\begin{tabular}{|l|c|c|c|c|c|}
\hline & $\mathrm{N}$ & Min $(\mathrm{cm})$ & Max $(\mathrm{cm})$ & Mean & Std. Deviation \\
\hline PS-VD of SAS & 30 & 1.9 & 4.0 & 3.32 & 0.513 \\
\hline PS-TD of SAS & 30 & 2.2 & 3.2 & 2.68 & 0.287 \\
\hline DS-TD of IAS & 30 & 2.0 & 3.5 & 2.73 & 0.384 \\
\hline DS - Biepicondylar width & 30 & 3.0 & 4.9 & 4.17 & 0.521 \\
\hline Maximum Humeral length & 30 & 26.2 & 34.9 & 31 & 2.00 \\
\hline Valid N & 30 & & & & \\
\hline
\end{tabular}

Table 2- Right humerus.

\begin{tabular}{|l|c|c|c|c|c|}
\hline & $\mathrm{N}$ & Min $(\mathrm{cm})$ & Max $(\mathrm{cm})$ & Mean & Std. Deviation \\
\hline PS-VD of SAS & 15 & 2.2 & 4.0 & 3.43 & 0.500 \\
\hline PS-TD of SAS & 15 & 2.2 & 3.2 & 2.78 & 0.285 \\
\hline DS-TD of IAS & 15 & 2.2 & 3.4 & 2.80 & 0.340 \\
\hline DS - Biepicondylar width & 15 & 3.5 & 4.9 & 4.24 & 0.390 \\
\hline Maximum Humeral length & 15 & 26.2 & 32.9 & 30.28 & 1.92 \\
\hline Valid N & 15 & & & & \\
\hline
\end{tabular}

Table 3- Left humerus.

\begin{tabular}{|l|c|c|c|c|c|}
\hline & $\mathrm{N}$ & $\operatorname{Min}(\mathrm{cm})$ & $\operatorname{Max}(\mathrm{cm})$ & Mean & $\begin{array}{c}\text { Std. } \\
\text { Deviation }\end{array}$ \\
\hline PS-VD of SAS & 15 & 1.9 & 3.8 & 3.22 & 0.519 \\
\hline PS-TD of SAS & 15 & 2.2 & 3.2 & 2.59 & 0.265 \\
\hline DS-TD of IAS & 15 & 2.0 & 3.5 & 2.67 & 0.426 \\
\hline DS - Biepicondylar width & 15 & 3.0 & 4.8 & 4.10 & 0.632 \\
\hline Maximum Humeral length & 15 & 28 & 34.9 & 31.74 & 1.864 \\
\hline Valid N & 15 & & & & \\
\hline
\end{tabular}

Table 4- Right humerus

\begin{tabular}{|c|c|c|c|}
\hline S.NO & Variables & COE & P \\
\hline P1 & PS-VD SAS & 0.26 & $<.001$ \\
\hline P2 & PS-TD SAS & 0.02 & $<.001$ \\
\hline D1 & DS-TD IAS & 0.16 & $<.001$ \\
\hline D2 & DS - BECW & 0.03 & $<.001$ \\
\hline
\end{tabular}

Table 5 - Left humerus

\begin{tabular}{|c|c|c|c|}
\hline S.NO & Variables & COE & P \\
\hline P1 & PS-VD SAS & 0.06 & $<.001$ \\
\hline P2 & PS-TD SAS & 0.31 & $<.001$ \\
\hline D1 & DS-TD IAS & 0.13 & $<.001$ \\
\hline D2 & DS -BECW & 0.08 & $<.001$ \\
\hline
\end{tabular}

\section{Discussion}

The length of long bones play a vital role in the estimation of stature of an individual. In the archaeological approach, stature is estimated from the human skeletal remains which is essential step in assessing- health, sexual dimorphism and general body size ${ }^{[14]}$. The estimation of living stature can be done from the humeral length in the absence of more appropriate long bones such as the femur andtibia ${ }^{[10]}$.

The humerus is the longest and the largest bone of the upper limb and it is very important to identify the humeral length from the segmental measurements ${ }^{[9]}$. Steele and Mckern ${ }^{[10]}$ defined a method based on the proportionality between the determined distances among the fixed points of the bones and their total length.

In forensic investigations and anthropometric studies, the mean value of the total humerus length gives important evidence to indicate the characteristic features of a population ${ }^{[6-8]}$. In Forensic anthropology, the estimation of stature from the bones plays an important role in the identification of missing persons ${ }^{[16]}$. 
Regression analysis is a more appropriate method for defining the relationship between the length of the long bones andliving height of individuals, and between the length of the measurements of the long bone fragments and their maximum length ${ }^{[15]}$.

In present study, the data was sex aggregated, the accuracy in estimating the stature would be obtained when the sex was available ${ }^{[9]}$. But still, Petersen ${ }^{[13]}$ noted that the differences of the femur length were independent of sex. Estimation of the length of long bone from its fragments, is done by using the accurate landmarks as mandatory. Usually, the transverse diameter of diaphysis are not appropriate for estimating the length because of their inability in defining the precise landmarks. Therefore, the only left over location points are measured on the fragments of proximal or distal diaphysis. Hence, for our present study, the dimensions of the proximal and the distal segments of the humeri alone are selected.

In our present study, we used regression equations to measure the length of the humerus, the right and left sides separately in a Telangana State population, which have not yet reported.Considering the proximal measurements, the vertical diameter of the superior articular surface alone showed significance in estimating the maximum length of the humerus on the right side. However, on the left side, both the vertical diameter of the superior articular surface as well as the transverse diameter of the inferior articular surface exhibited significant correlation.

\section{Conclusion}

The results of our study conclude that it is possible to estimate the maximum length of the humerus from the measurements of proximal and distal fragments with relative accuracy. Our study may help the forensic, anthropometric and also archaeological investigations for the identification of the remains of unknown bodies by using regression equations in aTelangana State population.

\section{Acknowledgment}

We acknowledge great help received from the scholars whose articles are cited and included in the references of this manuscript.

\section{References}

[1]. Chavan K.D, Datir SB et al. Correlation of foot length with height amongst Maharashtrian population of India. Journal of Indian Academy of Forensic Medicine.2009; 31(4):334-337.

[2]. Patel S M et al. Estimation of height from measurements of foot length in Gujarat region. J AnatSoc India.2007; 56(1): 25-27.

[3]. Sanli SG, Kizilkanat ED et al. Stature estimation based on hand length and foot length.Journal of Clinical Anatomy.2005 Nov; 18(8):589-96.

[4]. Rastogi P, Nagesh KR et al. Estimation of stature from hand dimensions of north and South Indians. Leg Med (Tokyo). 2008 July; 10(4):185-9[2].

[5]. Dan Utpal,Mukhopadhy P.P.,Ghosh.T.K.,Biswas.S,Estimation of stature from fragment of long bone(Tibia) In Indian Benagalee population,J.Anat.Soc.India-2009;58(2);169-172.

[6]. Ozaslan A, Üßcan MY, Zaslan Ü et al. Estimation of stature from body parts. Forensic Sci Int. 2003; 3501:1-6.

[7]. Mall G, Hubig M, Buttner A, Kuznik J, Penning R, Graw M. Sex determination and the estimation of stature from the long bones of the arm. Forensic Sci Int. 2001; 117(1-2): 23-30.

[8]. Wright LE, Vasquez MA. Estimation of the length of incomplete long bones: Forensic standards from Guatemala Am J PhysAnthropol. 2003; 120: 233-251.

[9]. Williams PL, Warwick R, Dyson M, Bannister LH (edn). The humerus. In: Grays anatomy, 37th edn. Churchill Livingstone. 1989, pp 406.

[10]. Steele DG, McKern TW. A method for the assessment of the maximum long bone length and living stature from fragmentary long bones. Am J PhysAnthropol 1969; 31:215- 228.

[11]. Krishan K. Anthropometry In Forensic Medicine And Forensic ScienceForensic Anthropometry. International Journal of Forensic Science $2007 ; 2 / 1$.

[12]. Scheuer L. Application of osteology to forensic medicine. Clinical Anatomy. 2002; 15: 297-312

[13]. Petersen HC. On the accuracy of estimating living stature from skeletal length in the grave and by linear regression. International Journal ofOsteoarchaeology. 2005; 15: 106-114.

[14]. Hoppa RD, Gruspier KL. Estimating the diaphyseal length from fragmentary subadult skeletal remains: implications for palaeodemographic reconstructions of a southern Ontario ossuary. American Journal of Physical Anthropology. 1996; 100/3: 341354.

[15]. Krogman WM, Iscan MY. The Human Skeleton in Forensic Medicine. Springfield: Charles C. Thomas, 1986.

[16]. Ross AH, Konigsberg LW. New formulae for estimating stature in the Balkans. Journal of Forensic Sciences. 2002; 47/1: $165-167$. 